\title{
AVALIAÇÃO DAS CONDIÇÕES DE ARMAZENAMENTO DOS ALIMENTOS NA CENTRAL DE ABASTECIMENTO (CEASA) DE PALMAS - TO
}

\author{
Evaluation of food storage conditionsat the Supply Center (Ceasa) Palmas - TO. \\ Evaluación de las condiciones de almacenamiento de alimentos en la Central De \\ Abastecimento (Ceasa) de Palmas -TO.
}

\section{Jorquiania Ferreira Leite ${ }^{* 1}$, Abraham Damian Giraldo Zuniga ${ }^{1}$, Amanda Campos Feitosa ${ }^{1}$, Mariana Carvalho Barbosa ${ }^{1}$}

${ }^{1}$ Programa de Pós-graduação em Ciência e Tecnologia de Alimentos, Universidade Federal do Tocantins, Palmas, Brasil.

*Correspondência: Programa de Pós-graduação em Ciência e Tecnologia de Alimentos - Universidade Federal do Tocantins Av. NS 15, 109 Norte, Palmas, Tocantins, Brasil. CEP:77.010-090.e-mail agro.jorquiana@gmail.com

Artigo recebido em 30/08/2018 aprovado em 22/01/2019 publicado em 30/03/2019.

\begin{abstract}
RESUMO
A busca por alimentos saudáveis, com melhor qualidade e mais convenientes tem demonstrado tendência de expansão em supermercados e em grandes centros urbanos. Um dos fatores que merece destaque é a falta de conhecimento e planejamento dos produtores rurais quanto à comercialização de seus produtos de maneira mais rentável, fato que ocasiona uma série de consequências em cadeia, como falta de estrutura na colheita e póscolheita, que gera impactos nas áreas de armazenamento, transporte, embalagem, manipulação e processamento dos produtos hortícolas, desencadeando, assim, dificuldades na comercialização, como reduzida vida de prateleira, baixa qualidade, escassez de oferta e preços elevados. Diante disso, o presente trabalho teve como objetivo em avaliar as formas de acondicionamento dos principais produtos comercializados no CEASA (banana e citros) armazenados no CEASA de Palmas, coletando informações importantes que possibilitem conhecer a dimensão do mercado consumidor desses produtos, como os principais problemas enfrentados nas condições de armazenagem, fatores esses que podem reduzir o desperdício e agregar valor às frutas e hortaliças.
\end{abstract}

Palavras-chave: Armazenamento, Pós-colheita, hortifruti

\section{ABSTRACT}

The search for healthier, better quality and more convenient food has shown a tendency to expand in supermarkets and in large urban centers. One of the factors that deserve to be highlighted is the lack of knowledge and planning of rural producers regarding the commercialization of their products in a more profitable way, a fact that causes a series of chain consequences, such as a lack of structure in the harvest and post-harvest, which generates impacts on the areas of storage, transportation, packaging, handling and processing of vegetables, thus triggering marketing difficulties such as reduced shelf life, poor quality, shortage of supply and high prices. The objective of this study was to evaluate the packaging of the main products marketed in CEASA (banana and citrus) stored in the CEASA of Palmas, collecting important information that allows to know the size of the consumer market of these products, as the main problems conditions, which can reduce waste and add value to fruits and vegetables.

Keywords: Storage, Post-harvesting, hortifruti

\section{RESUMEN}

La búsqueda de alimentos saludables, con mejor calidad y más convenientes, ha mostrado tendencia de expansión en supermercados y en grandes centros urbanos. Uno de los factores que merece destacarse es la falta de conocimiento y planificación de los productores rurales en cuanto a la comercialización de sus productos de manera más rentable, hecho que ocasiona una serie de consecuencias en cadena, como falta de estructura en la cosecha y post-cosecha, que genera los impactos en las áreas de almacenamiento, transporte, embalaje, manipulación y procesamiento de las hortalizas, desencadenando así dificultades en la comercialización, como 
reducida vida de estante, baja calidad, escasez de oferta y precios elevados. En el presente trabajo, el presente trabajo tuvo como objetivo en evaluar las formas de acondicionamiento de los principales productos comercializados en el CEASA (banana y cítricos) almacenados en el CEASA de Palmas, recogiendo informaciones importantes que posibilite conocer la dimensión del mercado consumidor de esos productos, como los principales problemas enfrentados en las condiciones de almacenamiento, factores que pueden reducir el desperdicio y agregar valor a las frutas y hortalizas.

Descriptores: Almacenamiento, post-cosecha, agricultura.

\section{INTRODUÇÃO}

Atualmente o Brasil apresenta como um país com grande potencial agrícola, possui uma área de terras agricultáveis férteis de 388 milhões de hectares e quase $13 \%$ de toda a água doce disponível no planeta (Ministério da Agricultura, Pecuária e Abastecimento - MAPA, [200-]) vem se revelando uma peça importante para o abastecimento de alimentos no mundo.

De acordo Organização das Nações Unidas para a Agricultura e Alimentação (FAO), ainda existe um grande paradoxo quando se fala em oferta e demanda de alimentos. Estima-se que a produção mundial precisa crescer $70,0 \%$ até 2050 para erradicar a fome, no entanto, cerca de $40,0 \%$ do que produzimos é desperdiçado (FAO, 2011).

Um dos fatores que acarretam as perdas de alimentos além da colheita indequada são o uso de embalagens inadequadas, transporte impróprio, não uso de refrigeração, desconhecimento de técnicas de manuseio, disponibilização inadequada nas gôndolas e excesso de toque nos produtos pelos consumidores (FAO, 2009).

Geralmente as perdas são atribuídas há causas bióticas (doenças patogênicas), abióticas (distúrbios fisiológicos ou doenças não patogênicas) e principalmente causas físicas (injúrias mecânicas) (MARTINS; FARIAS 2000).

As frutas e hortaliças frescas possuem grande proporção de água em sua composição, o que motiva a grande perca de produtos, dificultando atender a demanda, pois o consumidor está cada vez mais exigente por qualidade (MELO, 2016).

No cenário mundial onde a população está cada vez em busca de uma alimentação saudável, além da necessidade em consumir produtos naturais e orgânicos, a preocupação dos consumidores está voltadapara as ocorrências de contaminações e da má qualidade de produtos comercializados nas centrais de abastecimento (MELO, 2016).

Nesse sentido, é importante que a análise dos resultados encontrados nesse trabalho de pesquisa contribuam com o crescimento do agronegócio, um fator importante $\mathrm{n}$ econonomia brasileira, visto que, não basta apenas considerar o país um potencial fornecedor mundial de alimentos se não houver investimentos que possibilitem a aplicação de tecnologias sustentáveis e economicamente viáveis (MAPA, 2010).

Relevantes são os fatores que contribuem para o desperdício de alimentos, sendo que as principais razões encontram-se na falta de conhecimento técnico, pessoal treinado e habilitado, o uso de práticas inadequadas e principalmente no desconhecimento de técnicas adequadas de manuseio pós-colheita (CENCI, 2000).

$\mathrm{O}$ presente trabalho tem como objetivo avaliar as condições de armazenamento dos frutos na Central Estadual de Abastecimento de Alimentos (CEASA). 


\section{MATERIAIS E MÉTODOS}

A Central de Abastecimento do TocantinsCEASA foi inaugurada em 04 de Junho de 2009 no município de Palmas - Tocantins, fica localizado na quadra APE-01, lote 01, Avenida São Paulo Loteamento Jardim Paulista Setor Industrial Sul, com horário de funcionamento de segunda a sexta-feira, das 6 às 14 horas. Em relação a sua estrutura física possui 02 (dois) galpões de $1.800 \mathrm{~m}^{2}$ cada, um com 12 boxes e o galpão do produtor, denominado popularmente de "pedra".

$\mathrm{O}$ centro de Abastecimento de Palmas (Tocantins) possui um total de 300 produtores, sendo esses produtores dos municípios de Palmas, Gurupi, Araguaína, projetos São João (próximo a Palmas), e o projeto Manoel Alves.

Atualmente (8) oito empresas operam na CEASA, todas comercializando frutas e verduras, não somente produtos do estado, porém também produtos oriundos de regiões que não são produzidos no estado por razões de fatores climáticos, como por exemplo, a uva.

A metodologia usada para o desenvolvimento desse trabalho foi do tipo exploratória, realizando pesquisas bibliográficas, documentais e visitas no estabelecimento (GIL, 1999).

Desse modo, foram realizadas visitas no CEASA com o intuito em conhecer o seu funcionamento e acompanhar as formas de armazenamento dos produtos e realizados registros fotográficos. Além disso, coletou-se as temperaturas das câmeras de alimentos refrigerados.

Portanto, para obter alimentos seguros, é importante a adoção de medidas que minimizem suas perdas por meio de técnicas de estocagem. Para isso, é fundamental a implantação de boas práticas de manipulação de alimentos, as quais são estabelecidas pelas legislações brasileiras da Agência Nacional de Vigilância Sanitária n 343, de 11 de maio de 2017.
Figura 1. Localização Central de Abastecimento

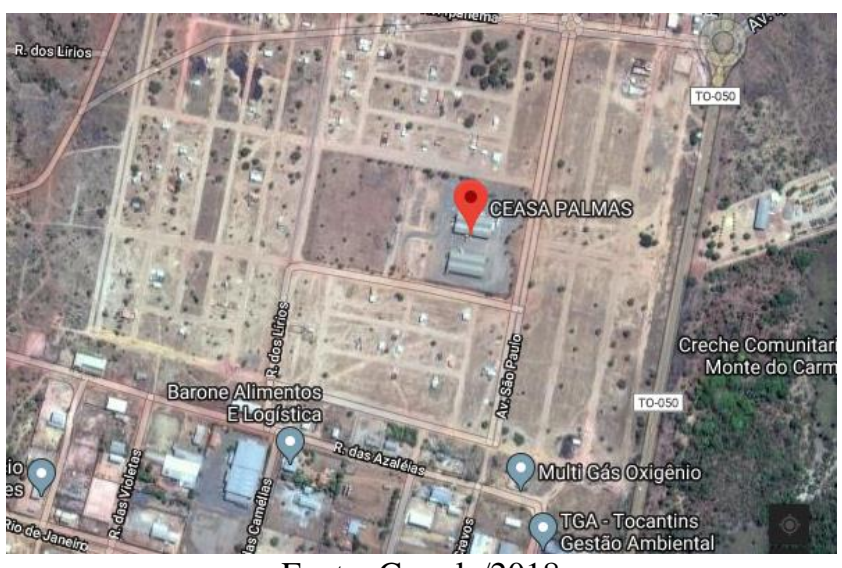

Fonte: Google/2018

\section{RESULTADOS E DISCUSSÃO}

\section{Condições de armazenamento dos frutos}

No presente momento a Central de Abastecimento de Palmas fez nos dois últimos anos uma estimativa de aproximadamente 14 mil toneladas de alimentos entre folhosos, legumes, frutas, verduras e demais produtos classificados como hortifrútis são consumidos por ano por aproximadamente $381,5 \mathrm{mil}$ habitantes. Segundo dados do IBGE (2011) a produção de hortifrúti das regiões de Gurupi, Palmas e Araguaína chegam a 7.299 toneladas.

Os produtos mais vendidos no CEASA são: batata, cebola, ovo, banana, tomate, melancia e laranja. Os produtos são vendidos para supermercados de Palmas, Gurupi e Araguaína. No estabelecimento há escassez da falta de estrutura para armazenar alimentos oriundos de outros municípios.

No decorrer da pesquisa conheceram-se as diferentes formas de armazenagem dos produtos em geral no estabelecimento, no entanto foi enfatizado os que se destacaram em relação ao consumo e produtos, sendo eles, a banana em geral, (nanica e prata), e citros (limão e laranja).

Geralmente as embalagens usadas nas Centrais de Abastecimento são caixas de papelão, madeira e plástico, ou seja, são terciárias. Como os produtos são vendidos em grande escala para 
supermercados e grandes redes varejistas, os produtos são alocados em caixas para posteriormente receberem embalagens personalizadas ou simplesmente ficarem em exposição.

A Associação Brasileira de Normas Técnicas classifica as embalagens em: primárias: contém o produto, pode ser a medida de produção e a unidade de comercialização no varejo, secundária: é o acondicionamento das embalagens primárias, terciária: contentores de materiais resistentes para contenção das embalagens secundárias, quaternária: unitização das embalagens terciárias para armazenagem e transporte, quinto nível: para preservação especial ou envio a distância (embalagens especiais).

$\mathrm{Na}$ tabela a seguir está exposto o demonstrativo de consumo em toneladas da produtividade referente ao ano de 2017, disponibilizadas no site do CEASA.

Tabela 1 - Demonstrativo de consumo em toneladas

\begin{tabular}{ll}
\hline PRODUTOS (t) & PRODUÇÃO (t) \\
\hline BANANA & 2892,764 \\
LARANJA & 2834,000 \\
LIMÃO & 346,375 \\
\hline
\end{tabular}

Fonte: CEASA (2017)

De acordo, com a Figura 02 nota-se os produtos com maior quantidade recebida na Central de Abastecimento de Palmas, sendo de Citros e bananas (Prata e Nanica), tendo a produção de citros um maior destaque.

Figura 02. Percentual de produção em toneladas referente ao ano 2017

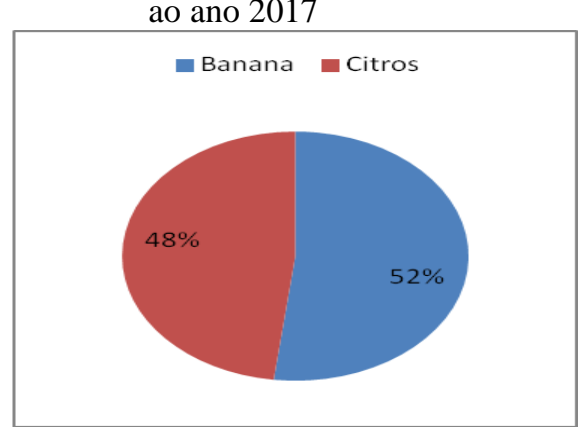

A produção de citros in natura para $\mathrm{o}$ mercado interno e externo tem-se destacado pela crescente necessidade da melhoria da qualidade dos frutos. No mercado interno, além do consumo da fruta, destaca-se a demanda de laranjas, tangerinas e limões para o preparo de suco fresco (IAC, 2005). Além desse fator, pode-se citar que os citros são mais resistentes que a banana em relação em relação ao manejo de pragas, transporte, e armazenagem.

O armazenamento dos alimentos compreendem na manutenção de produtos e ingredientes em um ambiente que proteja sua integridade e qualidade. Produtos acabados e matérias-primas devem ser armazenados segundo as boas práticas respectivas, de modo a impedir a contaminação e/ou a proliferação de microorganismos e proteger contra a alteração ou danos ao recipiente ou embalagem.

Durante todo o período do armazenamento deve ser exercida uma inspeção sistemática dos produtos acabados, a fim de que somente sejam expedidos alimentos aptos para ao consumo humano e sejam cumpridas a especificações de armazenamento quando existirem.

\section{PRODUTOS COMERCIALIZADOS}

De acordo com a visita realizada no estabelecimento foram realizadas coletas das formas de acondicionamento, temperatura e umidade dos produtos comercializados no CEASA- Palmas.

\section{BANANA (Musa spp)}

Um dos produtos que possui maior consumo e produção de armazenamento foram as bananas que são acondicionadas no local com média em torno de três a quatro dias até a sua comercialização, para retardar seu amadurecimento precisam ser condicionadas em câmeras de refrigeração entre uma 
temperatura de $10^{\circ}$ e $14^{\circ} \mathrm{C}$. As variedades disponíveis são banana prata, nanica, e terra.

A refrigeração pode ser usada como meio de conservação temporária até que se aplique outro método de conservação. A maior parte dos alimentos alteráveis pode ser conservada por refrigeração, durante um tempo limitado (EMRAPA, 2000). Os produtos perecíveis (alimentos in natura, produtos semi-preparados ou preparados e prontos para o consumo) precisam de condições especiais de temperatura para conservação (ANVISA, 2002).

O armazenamento sob refrigeração utiliza temperaturas um pouco acima do ponto de congelação. Nesta etapa os alimentos são armazenados em temperaturas entre $0^{\circ}$ e $10^{\circ} \mathrm{C}$ (EMBRAPA, 2000).

As temperaturas baixas são utilizadas para adiar as reações químicas e a atividade enzimática, como inibir o crescimento e a atividade dos microrganismos, sem destruí-los. Quanto menor for a temperatura, menores serão a ação química, enzimática e o crescimento microbiano (RAMOS, SOUSA E BENEVIDES, 2004).

O resfriamento rápido dos produtos é importante na conservação e no prolongamento da vida útil dos produtos, pois altas temperaturas afetam a qualidade das frutas e hortaliças ao interferir nos processos vitais, como: a) respiração; b) maturação e a produção de etileno e outros voláteis; c) perda de peso (H2O); e desenvolvimento e disseminação de microorganismos (CENCI, 2006).

Conforme Kader (2002) e Neves (2009), para suprir as demandas do mercado, os frutos climatéricos, como a banana, devem ser colhidos na maturidade fisiológica. Entretanto, a banana colhida com completo desenvolvimento fisiológico amadurece de forma desuniforme. Com o intuito em obter o amadurecimento uniforme, pode-se utilizar o processo de climatização (BOTREL et al., 2003).
A banana apresenta alto nível de etileno durante o amadurecimento. Portanto, considerando se que manutenção das características sensoriais do produto, faz-se necessário utilizar tecnologias que não acelerem demasiadamente a maturação (ROCHA, 2005).

Figura 03. Armazenamento da banana em caixa de

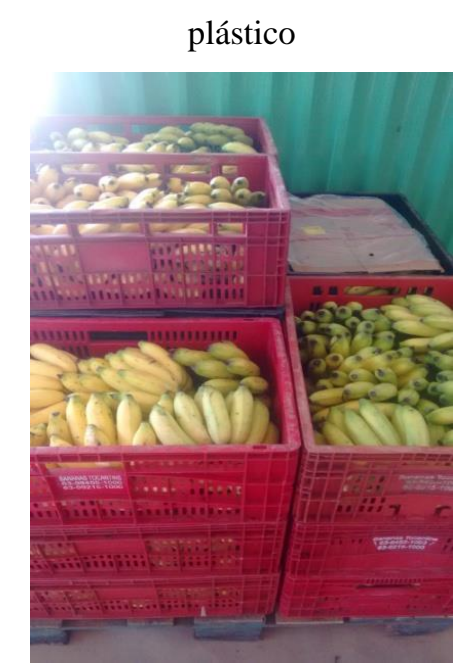

Figura 04. Armazenamento da banana em câmera frias sobre baixas temperaturas

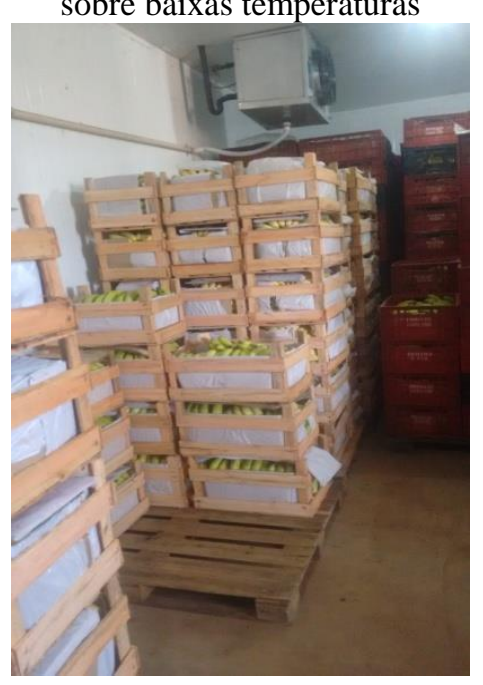

A armazenagem da banana ocorre por meio de caixa de madeira e papelão. De acordo com Silva (2006) esse tipo de embalagem facilita o transporte e acomodação de hortifrútis. Além de possuírem vantagens tal como baixo preço e elevada resistência.

No entanto, apresentam desvantagens como unitização da carga, sugividades, e facilidade para machucar o produto acarretando perdas. Em relação aos métodos de armazenamento no CEASA podem 
ser melhoradas com maiores pontos de refrigeração e acondicionamento não somente por caixas de plásticos ou papelão porém com o uso de tecnologias para maior capacidade de produtos e/ou variedades com o objetivo em reduzir injúrias, danos físicos e mecânicos que chegam em torno de $6 \%$.

\section{CITROS (Laranja e Limão)}

Os produtos citros oriundos de São-Paulo, Goiás, Minas-Gerais. Assim como a banana, o transporte e acondicionamento dos citros são realizados em caixas de plástico.

Dentre principais percas pode-se mencionar o transporte e acondicionamento nas caixas com entrada de sujividades, ou mal acondicionamento. Para as laranjas (Citrus sinesis) na Central de Abastecimento não há nenhum tratamento de estocagem para conservá-la por mais tempo. São realizadas a desinfecção e retiradas das sujividades da laranja após a colheita no campo e armazenadas em temperatura ambiente até o recolhimento para os supermercados.

Quando transportadas em mal estado a laranja pode apresentar ferimentos que facilitam a entrada de fungos e bactérias que ocasioarão no aprodrecimento precoce do fruto (IAC,2005). O período de acondicionamento na Central de Abastecimento gira em torno de dois a três dias até o transporte.

As condições de pós-colheita promovem alterações fisiológicas tal como ataque por patógenos, limitam o uso do fruto in natura, bem como comprometer seu valor comercial, ocasionando perdas econômicas (NASCIMENTO et al., 2005). Desse modo é importante prevenir esse uso por meio do acondicionamento e transporte para reduzir as perdas.

Existem algumas técnicas para reduzir essas perdas, pelas quais podem ser mencionadas, sendo elas o controle de temperatura, umidade e o uso de embalagens adequadas (OLIVEIRA e CEREDA, 1999).

Como já mencionado a refrigeração é um dos métodos mais eficazes, na manutenção da qualidade e comercialização dos produtos hortifrutícolas; as funções da refrigeração são retardar os processos metabólicos e diminuir a ocorrência de podridão (BRACKMANN et al., 2008). Todavia, pode causar distúrbios fisiológicos, como o dano de frio, caso a temperatura de estocagem dos frutos cítricos seja inferior à Temperatura Mínima de Segurança (TMS) (KLUGE et al., 2007). As frutas cítricas demonstram sensibilidade a baixas temperaturas, que se manifesta por meio da morte de células da casca.

Para o armazenamento refrigerado de laranja, a temperatura recomendada entre $3-9^{\circ} \mathrm{C}$ e UR de 85 $90 \%$, com as frutas podendo ser armazenadas durante 3 a 8 semanas (CHITARRA e CHITARRA, 2005).

Outro método interessante em armazenar produtos cítricos para manter maior durabilidade seria o uso de atmosfera modificada (AM), em que o consumo de $\mathrm{O} 2$ e a produção de $\mathrm{CO} 2$ durante a respiração do produto alteram a composição gasosa do ambiente da embalagem até um novo ponto de equilíbrio, com a criação de uma nova atmosfera gasosa no interior da embalagem.

As embalagens de produtos alimentícios podem ser de metal, plástico, vidro ou papel. $\mathrm{Na}$ figura abaixo observa-se o transporte por meio das caixas de plástico. O seu uso no mercado de embalagens tem crescido em função dos tipos de embalagens, o que pode ser atribuído à melhoria contínua dos plásticos, ampla versatilidade e baixo custo (GILES e BAIN, 2001).

O material usado para preservação do alimento e seus nutrientes influencia a ação de fatores ambientais (tais como luz, umidade, oxigênio e microorganismos) de maneira que venha dificultar o 
contato entre o ambiente externo e o produto em seu interior. Além de assegurar a integridade do produto durante $\mathrm{O}$ transporte e armazenamento (ROBERTSON, 1993; SARANTÓPOULOS et al., 2002).

\section{CONCLUSÃO}

Com os resultados foi possível constatar que as condições de temperatura e umidade para a climatização das bananas estão de maneira segura, ou seja, induzindo o amadurecimento sem, contudo, diminuir drasticamente, a qualidade sensorial e a vida útil dos frutos.

Em relação aos citros, notou-se que a Central de Abastecimento de Palmas não o armazenam por longo período e que os produtos detêm a margem de segurança de estoque.

Com isso, precisam ser melhoradas as formas de acondicionamentos dos produtos com maiores investimentos econômicos seja na estrutura do ambiente, seja em aumento de ambientes refrigerados para estocagem dos produtos recebidos, modernização dos ambientes e uso de novas tecnologias de armazenagem.

Desse modo, esse trabalho possui fontes de conhecimento para maior informação, percepção da população e, persuadir atenção das políticas públicas para um maior investimento no local de estudo.

Todos os autores declararam não haver qualquer potencial conflito de interesses referente a este artigo.

\section{REFERÊNCIAS}

ANVISA, 2002 - Resolução-RDC Anvisa n²75, de 21 de outubro de 2002. Disponível em: < portal.anvisa.gov.b>. Acesso em 30 jan. 2018.
BOTREL, N., SILVA, O.F., BITTENCOURT, A.M. Procedimentos pós-colheita. In: CAMPOS, R. P.; VALENTE, J. P.; PEREIRA, W. E. Conservação pós-colheita de banana cv. Nanicão climatizada e comercializada em Cuiabá - MT e região. Revista Brasileira de Fruticultura, Jaboticabal, v. 25, n. 1, p. 172-174, 2003.

CENCI, S.A. Perdas pós-colheita de Frutos e Hortaliças. EMBRAPA/CTAA, Rio de Janeiro 2000.

CENCI, S. A. . Boas Práticas de Pós-colheita de Frutas e Hortaliças na Agricultura Familiar. In: Fenelon do Nascimento Neto. (Org.). Recomendações Básicas para a Aplicação das Boas Práticas Agropecuárias e de Fabricação na Agricultura Familiar. 1a ed. Brasília: Embrapa Informação Tecnológica, 2006, v., p. 67-80.

CEASA MINAS. Ministério da Agricultura, Pecuária e Abastecimento. AVALIAÇÃO DO MERCADO DE FRUTAS E HORTALIÇAS EMBALADAS, MINIMAMENTE PROCESSADAS, ORGÂNICAS E DESIDRATADAS NA CAPITAL DE MINAS GERAIS. Contagem 2010.

GIL, A.C. Métodos e técnicas de pesquisa social/ Antônio Carlos Gil. - 6. Ed. - São Paulo: Atlas, 2008.

GILES, GA, Bain, DR. Technology of Plastics Packaging for the Consumer Market. Sheffield: Sheffield Academic Press, 2001.

FAO: um terço dos alimentos produzidos por ano é desperdiçado. Disponível em: Acesso em 19 de maio 2011.

JUNIOR, D. M. NEGRI, J. D. De José. FIGUEIREDO, Orlando de. JUNIOR, J. P. IAC Instituto Agronômico - CITROS: principais informações e recomendações de cultivo. Disponível em: <http://www.iac.sp.gov.br/imagem_informacoestecno logicas/43.pdf>. Acesso em: 29 jan 2018;

KADER, A.A. Postharvest biology and technology: an overview. In: KADER, A.A. (Ed.). Postharvest technology of horticultural crops. 3rd ed. Berkeley: University of California, 2002. p. 39-47.

MARTINS; FARIAS. Produção de alimentos x desperdício: tipos, causas e como reduzir perdas na produção agrícola - revisão. Revista da FZVA Uruguaiana, v. 9, n. 1, p. 20-32. 2002.

MELO, T.B. de. GERENCIAMENTO DAS ATIVIDADES LOGÍSTICAS DA CEASA DE PALMAS-TO. Instituto Federal de Ciência, Estudo e Tecnologiado Tocantins campus Porto Nacional 
2016. Disponível em:< ile:///C:/Users/Trabalho/Downloads/TCC_Tercilenes $\% 20$ Batista\%20de\%20Melo\%20(1).pdf>. Acesso em 11 jan. 2018.

MACHADO, R. L. P. Boas práticas de armazenagem na indústria de alimentos. Rio de Janeiro: Embrapa Agroindústria de Alimentos, 2000. 28p. (Embrapa Agroindústria de Alimentos. Documentos, 42).

ROBERTSON, G., L. Food Packaging: principles and practice. New York: Marcel Drekker; 1993. 680 p.
ROCHA, A. Uso de permanganato de potássio na conservação pós-colheita de banana 'Prata'. 2005. 82 f. Dissertação (Mestrado) - Universidade Federal de Viçosa, Viçosa, 2005.

SILVA, G.V. Da. A complexidade do sistema de adoção de embalagens adequadas para o setor hortifrutícolas. Monografia do programa de pósgraduação da Universidade Federal de Lavras. Minas Gerais, 2006. 